EDUCATION

Research, Innovation and Solutions on-line ${ }^{2}$
PSYCHOLOGY

$1+D+i$
Electronic Journal of Research in Educational Psychology

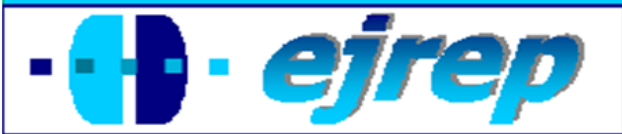

\title{
Malos comportamientos de los alumnos en las clases de Educación Física: una muestra desde Turquía
}

\section{Oğuzhan Yoncalık}

Facultad de Pedagogía, Departamento de Educación Física y Deportes, Universidad de Kırıkkale, Kırıkkale

\section{Turquía}

Correspondencia: Oguzhan Yoncalik. Kirikkale Üniversitesi, Egitim Fakültesi. Beden Egitimi ve Spor Ögretmenligi Bölümü. Kampus, 71450, Yahsihan. Kirikkale, Turquía. E-mail: yoncaliko@gmail.com

(C) Education \& Psychology $\mathrm{I}+\mathrm{D}+\mathrm{i}$ and Editorial EOS (Spain) 


\section{Resumen}

Introducción. Durante la preparación del plan de la lección, el profesor puede diseñar el objeto de enseñanza, el método de enseñanza y todas las actividades relacionadas de antemano, y todos ellos se organizan de acuerdo con el entorno más adecuado del que se dispone. Sin embargo, los estudiantes con mala conducta, según la experiencia, parecen ser el factor más importante que dificulta la instrucción, a pesar de los esfuerzos realizados por el profesor durante las clases para una gestión eficaz del tiempo. El objetivo de este estudio es presentar información sobre los tipos de mala conducta de los estudiantes, según los profesores de educación física, y la frecuencia con la que se producen.

Método. Este estudio se ha realizado sobre 102 profesores de educación física que trabajan para centros de educación primaria y secundaria de los centros urbanos de Kirikkale, Zonguldak, Artvin, Estambul durante el período de primavera del curso 2007-2008. Los datos han sido recogidos a través de una escala elaborada ad hoc. Los datos obtenidos se evaluaron de forma general al principio, después fueron analizados e interpretados según el género de los profesores y el tipo de centro (primaria / secundaria).

Resultados. Según los profesores, el mal comportamiento de los estudiantes es poco frecuente, y son situaciones negativas que se pueden superar, en colaboración con los directores del centro. Otro resultado importante que se presenta en este estudio es que, en general, las profesoras encuentran más estudiantes con mal comportamiento que los profesores.

Discusión y Conclusión. Según los profesores de educación física, los estudiantes de los centros de secundaria son más pasivos, reticentes, indiferentes y retirados durante las lecciones de educación física, que los alumnos de los centros de primaria. En general, con más edad o más nivel, más se encuentran los malos comportamientos. La mala conducta varía de acuerdo con el nivel del curso.

Palabras Clave: Educación Física, mal comportamiento de alumnos, profesores.

Recibido: 05/05/09 Aceptación Inicial: 07/05/09 Aceptación Definitiva: 14/09/09 


\section{Introducción}

Al preparar el plan de la lección, el profesor puede diseñar el objeto de enseñanza, el método de enseñanza y todas las actividades relacionadas de antemano, y todos ellos se organizan de acuerdo con el entorno más adecuado disponible. Los malos comportamientos de los estudiantes durante las clases, tanto los comportamientos existentes como los que pueden surgir, parecen ser el factor más importante que dificulta la instrucción a pesar del esfuerzo que realizan los profesores durante las clases para una eficaz gestión de la conducta. La razón es que es imposible predecirlos de antemano aunque sí se le ocurra al profesor mientras hace su programación. Sin embargo, se puede argumentar que algunos de los malos comportamientos que exhiben los alumnos durante la clase incluyen algunos patrones de conducta estereotipados. Hasta existen modelos propuestos por muchos investigadores que especifican estos comportamientos y cómo hay que afrontarlos. Charles (1992) clasificó los malos comportamientos que identificaron los profesores del aula bajo cinco nombres y los explicó de la siguiente manera: (1) Ataque: Ataques físicos o verbales de los alumnos al profesor o a los compañeros, (2) Corrupción: hacer trampas, mentir, robar, (3) Desobedecer la autoridad: Resistirse ante lo que les piden los profesores, (4) Falta de respeto en el aula: Hablar en voz muy alta, comportamientos raros, pasearse por el aula, (5) Perder el tiempo: No realizar las tareas asignadas, mostrarse indiferente durante la clase, atender a cosas no relevantes con la lección.

En sus estudios, Goyette, Dore y Dion (2000) enumeraron los malos comportamientos de los alumnos para la asignatura de "educación física" bajo tres niveles. El primer nivel incluye los siguientes comportamientos: estar distraído, hablar, llegar tarde, no vestir el uniforme, salir del aula. Los comportamientos del segundo nivel se tratan de hacer el payaso, discutir, acoso, hacer ruido, alterar la actividad, saltarse las reglas de forma intencionada, dejar de participar en una actividad. En el tercer nivel se incluyen las críticas a los demás, destrucción de materiales, agresividad, conducta peligrosa, ser grosero, ridiculizar a los demás, resistirse a la instrucción. Supaporn, Dodds y Griffin (2003) 1levaron a cabo un estudio en el cual investigaron la percepción de malos comportamientos de los participantes en un entorno de clase de gimnasia del primer ciclo de educación secundaria. Observaron a un profesor de gimnasia y sus alumnos de primero y segundo de educación secundaria durante una unidad de 10 días de baloncesto. Se observaron todas las clases durante el período del estudio y los investigadores entrevistaron tanto al profesor como a los alumnos para recoger 
sus perspectivas sobre los malos comportamientos. Tanto el profesor como los alumnos consideraron que el mal comportamiento es no comportarse de la forma que se espera de los alumnos. El profesor y los alumnos también identificaron varios grados de mal comportamiento. Según ellos, los malos comportamientos van desde leves hasta graves. "Hacer el tonto" fue un ejemplo de un mal comportamiento leve, y tirar canastas mientras el profesor da instrucciones se consideró un mal comportamiento moderado. Por contraste, pelear se consideró un mal comportamiento grave. Además, la percepción de los alumnos respecto a los malos comportamientos variaba si participaron en una acción específica ellos mismos o alguien de su grupo de amigos. Se mostraban reticentes a identificar como mal comportamiento una acción si ésta ocurría dentro de su propia camarilla (Supaporn, Dodds y Griffin 2003).

En un estudio llevado a cabo en la Universidad de Çukurova, se vio que los malos comportamientos notados por los alumnos del departamento de "Enseñanza en el Aula" estaban de acuerdo con los resultados de la literatura existente, especialmente "Hablar fuera de tiempo", "Hacer ruido", "Interrumpir a otros," "Falta de atención", "Conversar" y "Movimientos inapropiados". Casi todos los participantes del estudio se centraron en tres características principales al definir los malos comportamientos de los alumnos: interrupción de la clase, dificultar la participación de los demás, y hacer intervenciones amenazadoras en clase (discutir, provocar, chivarse). Un alumno define el mal comportamiento así: "Para mí, el mal comportamiento es una conducta que impide a los demás concentrarse en las actividades de leer o escribir. También perjudica la continuidad de la instrucción o lección" (Atıc1, 2007). Supaporn (2000) define los malos comportamientos de los alumnos desde el punto de vista de los alumnos de 14-18 años. Los alumnos participantes en el estudio definieron los malos comportamientos como no hacer lo que el profesor les pedía o hacer lo que se les pedía que no hicieran. De acuerdo con los datos obtenidos en este estudio, los malos comportamientos de los alumnos se clasifican en acosar (criticar a los iguales, hacer daño a los iguales, discriminar), no prestar atención (vagar, hablar, usar lenguaje poco apropiado), no cumplir las reglas (no participar, no seguir las reglas de la clase, no seguir las reglas de la actividad, oponerse a las actividades) y otros (hacer trampas, pelear, fumar). Infantino y Little (2005) encontraron que las conductas enfatizadas como más presentes son también aquellas que más cansinas les resultan. Como resultado del análisis de los datos obtenidos a través de cuestionarios que se distribuyeron entre los alumnos, conductas tales como hablar fuera de turno, contestar mal, levantarse del asiento, comer, estorbar a otros niños, hacer ruidos 
innecesarios, desobedecer, agresiones físicas, falta de puntualidad, holgazanería / lentitud, desorden y otras se ven como las conductas más fastidiosas y más frecuentes. Al compararlas con las conductas más fastidiosas y más frecuentes que encuentran los profesores de secundaria, Little (2005) indicó que los resultados fueron casi los mismos. Se encontró que los comportamientos más frecuentes eran también los comportamientos más fastidiosos.

Stephens, Kyriacou y Tønnessen (2005) estudiaron cómo los profesores en prácticas en Noruega e Inglaterra explicaban los malos comportamientos de los alumnos. Como resultado de los análisis de datos obtenidos a través de este estudio, se clasificaron las conductas según seis categorías, explicadas de la siguiente manera: "1) Agresión hacia otros alumnos" (bullying; agresión física hacia otros alumnos; uso del teléfono móvil durante la clase), 2) "Conducta delictiva" (llevar al aula armas contundentes o armas blancas; estar bajo el efecto de sustancias), 3) "Desviación negativista" (saltarse las reglas del aula o del centro de manera persistente; discutir de manera hostil con el profesor; comentarios o contestaciones descarados o groseros al profesor; saltarse las clases o absentismo escolar), 4) "Desviación pasivo-agresiva" (levantarse de su asiento (o lugar de trabajo) sin permiso [si es la norma pedir permiso]; llegar tarde al centro o a la clase; hablar fuera de turno) 5) "Conducta antisocial" (comentarios racistas; vandalismo) y 6) "Conducta no relacionada con la tarea" (evitar el trabajo intencionadamente; interrumpir otros alumnos). Bru, Murberg y Stephens (2001) estudiaron los malos comportamientos de los alumnos considerando la asociación entre la estructura familiar y experiencias negativas de la vida. Intentaron evaluar los malos comportamientos de los alumnos a través del uso de una escala en la cual los alumnos podían evaluarse a sí mismos. Los investigadores enfatizaron que no había ninguna escala de uso común que identificara y evaluara los malos comportamientos de los alumnos. En sus estudios, afirmaron que se había usado una escala de 10 ítems como herramienta para recoger datos, ésta incluía comportamientos como bullying (maltrato entre iguales), provocar y pelear, conducta disruptiva y absentismo escolar. A través del análisis factorial llevado a cabo, se agruparon los malos comportamientos en dos dimensiones: como conducta antisocial hacia otros alumnos (discusiones y conductas conflictivas incluido el bullying) y la conducta negativista hacia los profesores (mala concentración, conductas inapropiadas, exhibición de mal genio hacia el profesor y absentismo escolar). Se descubrió que los malos comportamientos denunciados con más frecuencia entre los alumnos adolescentes participantes en el estudio fueron la pobre concentración y las conductas disruptivas. Bru, Stephens, y Torsheim (2002), en sus estudios con 3884 estudiantes de los cursos sexto y 
noveno de la educación primaria del sistema escolar de Noruega, subrayaron que existían correlaciones considerables entre la percepción de los alumnos sobre la gestión de clase y los malos comportamientos que ellos mismos reconocieron exhibir. Se expresó que, en general, diferencias en el tipo de gestión de la clase estaban relacionadas con los malos comportamientos de los alumnos.

En otro estudio sobre las percepciones de los alumnos respecto a las estrategias de disciplina usadas en el aula, en Australia, China e Israel, el acceso a tres plataformas nacionales diferentes permitió examinar la definición que daban 748 profesores y 5521 alumnos de varias estrategias de disciplina usadas por profesores y los malos comportamientos de los alumnos. Se observó que los profesores chinos eran menos castigadores y agresivos en comparación con los profesores israelíes y australianos, y que eran más encubridores y de apoyo para los alumnos. En los tres países, un aumento de estrategias agresivas en la gestión de la clase era el factor individual más relacionado con el mal comportamiento de los alumnos (Lewis, Romi, Qui y Katz, 2005). En otro estudio sobre las evaluaciones de profesores australianos y chinos con respecto a los malos comportamientos de alumnos, se hizo hincapié en que los profesores chinos por lo general relacionaban los malos comportamientos con factores familiares, mientras que los profesores australianos los asociaban con el talento (Ho, 2004). También, Liljequist y Renk (2007) encontraron que los profesores tenían más dificultad con alumnos introvertidos que con los extrovertidos.

Turnuklu y Galton (2001) establecieron que los comportamientos más frecuentes en las escuelas primarias turcas y británicas fueron el hablar a voces o cuando no estaba permitido, y los movimientos inapropiados. Las aulas de ambos países se parecían en este aspecto. Los profesores debían tratan con conductas moderadas más que con conductas graves. Se enfatizó que los comportamientos como insultar a los iguales, insultar al profesor, protestas al profesor, agresiones físicas a otros alumnos, coger algo sin permiso, y comer o beber cuando estaba prohibido eran conductas muy poco frecuentes en las aulas de ambos países. En su trabajo, Ding, Li, Li y Kulm (2008) se centraron en las percepciones de 244 profesores chinos, incluidos profesores de gimnasia, sobre los malos comportamientos de los alumnos; elaboraron un cuestionario para intentar recoger las opiniones de los profesores sobre la gestión de la clase y los malos comportamientos más frecuentes y más fastidiosos. Otro propósito del cuestionario era una mayor comprensión de las necesidades de los 
profesores a la hora de gestionar la clase con más habilidad. El mal comportamiento encontrado por los profesores con más frecuencia era el no atender, 46,3 por ciento. Esta conducta también se identificó como la más molesta y fastidiosa $(22,1 \%)$. La segunda conducta más frecuente fue la de hablar fuera de turno $(18,4 \%)$ mientras que la segunda más fastidiosa fue la lentitud (14,3\%). Según los profesores chinos participantes, el no atender era mucho más frecuente que hablar fuera de turno y más fastidioso que la lentitud. Esto discrepa con la investigación previa en países occidentales. En los estudios occidentales, el hablar fuera de turno era la conducta más frecuente y la más fastidiosa. Leung y Ho (2001) subrayaron un posible factor cultural. El orden del aula es más estructurado en Hong Kong que en el Reino Unido, debido la influencia de la cultura china, especialmente la ética de Confucio. Por consiguiente, se puede ver que estorbar a otros alumnos no era tan grave como en el estudio británico. En cambio, la falta de atención de los alumnos despertaba la preocupación de los profesores. Una muestra de conveniencia $(n=144)$ desde 10 escuelas primarias respondió a esta encuesta.

Merrett y Wheldall (1984; citado en: Ding et al., 2008) en su estudio sobre 119 maestros británicos de 29 escuelas primarias, concluyeron que el 62 por ciento de los maestros participantes comentaban mayormente los malos comportamientos de los alumnos encontrados con más frecuencia en el aula, tales como el hablar fuera de turno, molestar a los demás, faltar a clases y desobedecer. Estos investigadores obtuvieron resultados similares en otro estudio con 198 maestros británicos de 32 escuelas primarias en 1988, y en otro estudio con 166 maestros australianos (Wheldall y Beaman, 1994; citado en: Ding et al., 2008). Ambos estudios señalaron que el hablar fuera de turno era el mal comportamiento más frecuente y más fastidioso (Ding et al., 2008). Un estudio llevado a cabo en Inglaterra y Noruega recogió la opinión de 128 maestros de primaria, que cursaban un doctorado de pedagogía, sobre los malos comportamientos de los alumnos, su frecuencia, y las estrategias para afrontarlos. Como resultado del estudio, los comportamientos más frecuentes en términos de sus valores medios fueron: "hablar fuera de turno (p.ej. gritar, interrumpir, comentarios inapropiados o charloteo molesto durante la lección)", "evasión el trabajo intencionada (p.ej. tardar en empezar a trabajar, no traer libros o equipos importantes)", "Interrumpir a otros alumnos (p.ej. distraerles de su trabajo)", "hacer ruido innecesario (p.ej. arrastrar la silla, golpear objetos, u otras conductas ruidosas)", “Alboroto general, payasadas o perder de tiempo", "Llegar tarde a clase", mientras que los comportamientos menos encontrados fueron: "Traer armas blancas o armas contundentes al aula (p.ej. un cuchillo o una porra)", "Estar bajo la influencia de sustancias (p.ej. alcohol o drogas) al entrar al aula", 
"Agresión física hacia el profesor", "Discutir con el profesor de forma hostil", "Vandalismo (p.ej. romper o dañar mobiliario o cosas que pertenecen a otros alumnos, al profesor o al centro)", "Comentarios racistas", "Agresión física a otros alumnos (p.ej. empujarles o pegarles)", "Bullying (maltrato entre iguales)", "Usar el teléfono móvil durante la lección" (Kyriacou, Avramidis, Høie, Stephens, y Hultgrem, 2007).

\section{Método}

\section{Participantes}

Este estudio se llevó a cabo con 102 profesores de educación física, seleccionados al azar de centros de educación primaria y secundaria de la República de Turquía, Ministerio Nacional de Educación (T.C. MEB), situados en los centros urbanos de Kirıkkale, Zonguldak, Artvin, Estambul. Treinta y ocho eran mujeres y los 64 restantes eran hombres. En cuanto a su lugar de trabajo, 22 docentes mujeres trabajaban en centros de primarias y 16 en centros de secundaria; 37 docentes varones trabajan en centros de primarias y 27 en centros de secundaria. 59 de los docentes participantes en el estudio informaron que trabajaban para centros de primaria y 43 informaron que trabajaban para centros de secundaria. Se recogió datos a través de entrevistas cara a cara con los docentes. Estos docentes trabajaban en 73 centros diferentes en total. Bajo ciertas circunstancias actuales de Turquía, es una indicación positiva que un centro tenga un docente dedicado a la educación física. La experiencia profesional de los profesores de educación física participantes en el estudio varía de 2 a 25 años.

\section{Instrumento}

Para este estudio, consideramos necesaria una escala para recogida de datos. Después de una revisión meticulosa de la literatura nacional y extranjera sobre este tema, la escala (cuestionario) más exhaustiva que mejor cumplía los propósitos de este estudio, y la mejor para determinar los malos comportamientos de los alumnos encontrados durante las clases de educación física, fue la escala para educación física elaborada por Kulinna, Cothran y Regualos (2003). Se excluyeron algunos ítems de la versión de la escala en turco y se hizo una lista aleatoria de los ítems restantes al incluirlos en el estudio. Consideramos que algunos de los ítems coincidían parcialmente con otros y tenían significados similares. Por ejemplo, se 
consideró que "Pelear" entraba dentro del ámbito de "Ser provocador"; "Acoso sexual" dentro del ámbito de "Gestos obscenos"; "Salir del grupo en medio de una actividad" dentro del ámbito de "No participar"; "Mala deportividad" dentro del ámbito de "Jugar a lo bruto"; "Usar como excusa el período menstrual" dentro del ámbito de "Fingir estar enfermo".

Después de traducir la escala al turco, hicimos que dos docentes, ambos profesores de la Universidad de Düzce, volvieran a traducirla al inglés. Al compararlo con el texto original, el texto traducido no mostró ningún cambio semántico significativo. Los ítems de la versión original de la escala consistían generalmente de una o pocas palabras, haciendo posible pasar por esta fase sin ninguna dificultad. Después, se presentó la versión turca de la escala a tres pedagogos de la Facultad de Educación de la Universidad de Kırıkkale y se alcanzó un consenso sobre el hecho de que era compatible con la cultura turca. Ya que no se tomaron en cuenta en este estudio las estructuras factoriales de la escala original, y que la escala fue aplicada a participantes de una edad y carrera específicas, no hizo falta llevar a cabo un proceso de adaptación al turco de una manera estadísticamente significativa. En este estudio, cada respuesta dada por los participantes a cada ítem del cuestionario se evaluó por separado y las puntuaciones medias de las respuestas de los participantes a cada ítem se ordenaron desde la media menor hasta la media más alta. Si se deseara obtener resultados a través de los factores de la escala, se debería considerar el proceso de adaptación mencionado arriba. Es decir, al aplicarla a docentes o alumnos turcos, se debe realizar un estudio para ver en qué medida son válidas las estructuras factoriales. Es generalmente sabido que, faltando un consenso total, se recomienda llevar a cabo un análisis con un número de sujetos al menos tres veces mayor que el número de ítems incluidos en la escala, para comprobar su fiabilidad. En este estudio, como resultado del análisis de respuestas de 102 participantes a la escala compuesta de 43 ítems, el coeficiente de fiabilidad Cronbach Alfa fue ,87. Las respuestas al cuestionario se elegían entre "Nunca, Apenas, Pocas Veces, Bastante, Mucho" en una escala Likert de cinco puntos. Los alumnos generalmente llevaban siete a ocho minutos para completar el cuestionario. Se les dijo a los docentes participantes en el estudio que podían añadir comentarios adicionales en el reverso de las hojas del cuestionario para conseguir información que no cubrían los ítems del cuestionario.

\section{Análisis de datos}


Se pasaron los datos al programa SSPS 12.0 y se evaluaron. Para interpretar los datos obtenidos, se usó una prueba $\mathrm{t}$ independiente para grupos no relacionados (sexo: hombre / mujer; centro: primaria / secundaria).

\section{Resultados}

Los hallazgos obtenidos de los análisis de datos con diversas variables se presentan a continuación.

Como se puede comprobar en la Tabla 1, los malos comportamientos encontrados en las clases de educación física se clasificaron desde la frecuencia menor hasta la mayor, de acuerdo con los valores medios de las respuestas de los 102 docentes de educación física participantes en el estudio. Según la Tabla 1, los malos comportamientos que menos encuentran los docentes de educación física de los 73 centros son: "Exhibir símbolos de bandas o pandillas", "Llevar armas al aula", "Contestar mal al docente", "Escribir o pintar en las paredes", "Robar", "Interrumpir" y "Fumar". Esta carencia de problemas de conducta serios puede entenderse como un hallazgo positivo en cuanto al proceso educativo. Todos los ítems mencionados se encuentran entre las acciones disciplinarias notables de los centros. Puede decirse que estas conductas están más relacionadas con características psicosociales de los alumnos que con la estructura de la lección o con el docente. Son situaciones más bien negativas que pueden superarse en cooperación con la gestión del centro. También es otro hallazgo positivo el hecho de que se encuentren muy poco, o en absoluto.

Tabla 1. Clasificación de los malos comportamientos observados por los docentes en sus alumnos, según sus valores medios

\begin{tabular}{lll}
\hline \multicolumn{2}{l}{ Mal comportamiento de los alumnos } & Media \\
\hline 1 & Exhibir símbolos de bandas o pandillas & 1,48 \\
\hline 2 & Llevar armas al aula & 1,52 \\
\hline 3 & Contestar mal al docente & 1,66 \\
\hline 4 & Escribir o pintar en las paredes & 1,72 \\
\hline 5 & Robar & 1,76 \\
\hline 6 & Interrumpir & 1,80 \\
\hline 7 & Fumar & 1,82 \\
\hline 8 & Lloriquear & 2,00 \\
\hline 9 & Chulearse & 2,13 \\
\hline 10 & Pegársele físicamente al docente & 2,13 \\
\hline 11 & Tener una pobre imagen de sí mismo & 2,21 \\
\hline 12 & Faltar a clase o llegar tarde & 2,22 \\
\hline 13 & No seguir las instrucciones & 2,24 \\
\hline 14 & Gestos obscenos & 2,30 \\
\hline
\end{tabular}




\begin{tabular}{lll}
\hline 15 & Hacer trampas & 2,34 \\
\hline 16 & Fingir estar enfermo & 2,38 \\
\hline 17 & No participar & 2,40 \\
\hline 18 & No ponerse bien en fila & 2,40 \\
\hline 19 & Formar camarillas & 2,42 \\
\hline 20 & Mentir & 2,43 \\
\hline 21 & Moverse lentamente a propósito & 2,45 \\
\hline 22 & Decir continuamente "no puedo" & 2,45 \\
\hline 23 & Mascar chicles & 2,47 \\
\hline 24 & Realizar acciones peligrosas & 2,48 \\
\hline 25 & Pedir siempre que se le repitan las instrucciones & 2,56 \\
\hline 26 & Mostrarse tímido y retraído & 2,58 \\
\hline 27 & Ser perezoso & 2,58 \\
\hline 28 & Alterarse cuando pierde o se equivoca & 2,64 \\
\hline 29 & Discutir & 2,65 \\
\hline 30 & Burlarse de otros alumnos & 2,66 \\
\hline 31 & Olvidar su ropa de educación física & 2,70 \\
\hline 32 & Bullying, maltrato entre iguales & 2,74 \\
\hline 33 & Hablar & 2,77 \\
\hline 34 & Jugar a lo bruto & 2,78 \\
\hline 35 & No cuidar el equipo & 2,80 \\
\hline 36 & Ropa de educación física sucia & 2,84 \\
\hline 37 & Ser provocador & 2,87 \\
\hline 38 & Contestar mal a los alumnos & 2,92 \\
\hline 39 & Mostrar risitas tontas & 3,00 \\
\hline 40 & Empujar o pegar a los demás & 3,04 \\
\hline 41 & Chivarse & 3,05 \\
\hline 42 & Tener que ser siempre el primero o el mejor & 3,22 \\
\hline 43 & Llamar la atención & 3,23 \\
\hline & &
\end{tabular}

De acuerdo con los datos en la Tabla 1, los trece malos comportamientos que encuentran los docentes de educación física con más frecuencia, en base a sus valores de media, son: "Olvidar su ropa de educación física", "Bullying / maltrato entre iguales", "Hablar", "Jugar a lo bruto", "No cuidar el equipo" "Ropa de educación física sucia”, "Ser provocador", "Contestar mal a los alumnos", "Mostrar risitas tontas", "Empujar o pegar a los demás", "Chivarse", "Tener que ser siempre el primero o el mejor", "Llamar la atención". Cuando uno estudia los ítems clasificados en esta lista, puede argumentar que están relacionados entre ellos en 4 aspectos diferentes. El primero es el aspecto de valor económico representado por no cuidar o utilizar el equipo, al igual que el mal uso de la ropa de educación física (clasificados 31-35-36). En el segundo, los alumnos muestran una actitud provocadora o malas contestaciones unos con otros durante las lecciones (clasificados 35-34-37-38-40). El tercero es que los alumnos se pasen en conductas tales como hablar y reírse (clasificados 3339-41). El cuarto, que incluye los dos comportamientos más frecuentes, es las demandas innecesarias de los alumnos por ganar el favor del docente (clasificados 42-43). 
Todos los demás ítems recibieron valores de media muy similares (Tabla 1) y se consideran conductas que se encuentran en un nivel ni muy por abajo ni muy por encima de la media.

La Tabla 2 incluye resultados del análisis de la prueba t con datos referentes a los malos comportamientos de los alumnos encontrados por los docentes, según el tipo de centro. Según estos resultados, encontramos diferencias estadísticas en 11 de los 46 ítems:"Empujar o pegar a los demás” $(p=, 042)$, “Lloriquear" $(p=, 013)$, "No participar" $(p=, 036)$, “Chulearse” $(p=, 001)$, "Fingir estar enfermo" $(p=, 011)$, "Mentir" $(p=, 013)$, "Pedir siempre que se le repitan las instrucciones" ( $p=041)$, "Fumar" $(p=, 000)$, "Llevar armas al aula" $(p=, 041)$, "Mascar chicles" $(p=, 001)$, "Pegársele físicamente al docente" $(p=, 002)$. De acuerdo con los resultados del análisis de la prueba t, se encontró que los ítems "Mascar chicles", "Chulearse", "Fingir estar enfermo", "No participar", "Fumar", "Llevar armas al aula" fueron los comportamientos encontrados $(\mathrm{p}<, 05)$ con mayor diferencia por los docentes que trabajan en centros de secundaria, frente a los centros de primaria. Por el contrario, los ítems "Empujar o pegar a los demás", "Lloriquear", "Mentir", "Pedir siempre que se le repitan las instrucciones" y "Pegársele físicamente al docente" fueron los comportamientos encontrados por los docentes con mayor diferencia en los centros de primaria. Esta situación encontrada por docentes que trabajan en centros de primaria puede verse como propia del nivel evolutivo de los alumnos de primaria, según las edades de los mismos. Empujar o pegar a los demás y la exhibición de conductas sin pensar en el sentido moralmente negativo de estas conductas mostradas individualmente o juntamente con otros, son situaciones que pueden atribuirse especialmente a alumnos del primer ciclo de la escuela primaria.

Tabla 2. Valores medios de malos comportamientos según el tipo de centro (Educación Primaria / Secundaria) en el que trabajan los docentes

\begin{tabular}{|c|c|c|c|c|c|c|c|c|c|}
\hline Comportamientos & $\begin{array}{c}\text { Tipo } \\
\text { de } \\
\text { Cen.* }\end{array}$ & Media & $\mathbf{t}$ & $\mathbf{p}$ & Comportamientos & $\begin{array}{l}\text { Tipo de } \\
\text { Cen. }\end{array}$ & Media & $\mathbf{t}$ & $\mathbf{p}$ \\
\hline \multirow{2}{*}{$\begin{array}{l}\text { Empujar o pegar a los } \\
\text { demás }\end{array}$} & Pri* & 3,22 & \multirow{2}{*}{1,885} & \multirow{2}{*}{, 042} & \multirow{2}{*}{ Chulearse } & Pri & 1,89 & \multirow{2}{*}{3,454} & \multirow{2}{*}{, 001} \\
\hline & $\mathrm{Sec}^{*}$ & 2,76 & & & & $\mathrm{Sec}$ & 2,55 & & \\
\hline \multirow{2}{*}{$\begin{array}{l}\text { Contestar mal a los } \\
\text { alumnos }\end{array}$} & Pri & 2,96 & \multirow{2}{*}{656} & \multirow{2}{*}{, 513} & \multirow{2}{*}{ Fingir estar enfermo } & Pri & 2,20 & \multirow{2}{*}{2,589} & \multirow{2}{*}{,011 } \\
\hline & $\mathrm{Sec}$ & 2,82 & & & & Sec & 2,74 & & \\
\hline \multirow{2}{*}{ Gestos obscenos } & Pri & 2,38 & \multirow{2}{*}{, 898} & \multirow{2}{*}{, 372} & \multirow{2}{*}{$\begin{array}{l}\text { No seguir las } \\
\text { instrucciones }\end{array}$} & Pri & 2,13 & \multirow{2}{*}{1,286} & \multirow{2}{*}{,202 } \\
\hline & $\mathrm{Sec}$ & 2,17 & & & & $\mathrm{Sec}$ & 2,42 & & \\
\hline \multirow{2}{*}{ Jugar a lo bruto } & Pri & 2,86 & \multirow{2}{*}{,952 } & \multirow{2}{*}{, 344} & \multirow{2}{*}{ No cuidar el equipo } & Pri & 2,75 & \multirow{2}{*}{,648 } & \multirow{2}{*}{, 519} \\
\hline & $\mathrm{Sec}$ & 2,65 & & & & $\mathrm{Sec}$ & 2,89 & & \\
\hline \multirow{2}{*}{ Ser provocador } & Pri & 2,93 & \multirow{2}{*}{,485 } & \multirow{2}{*}{,629 } & \multirow{2}{*}{$\begin{array}{l}\text { No ponerse bien en } \\
\text { fila }\end{array}$} & Pri & 2,36 & \multirow{2}{*}{,276 } & \multirow{2}{*}{, 783} \\
\hline & $\mathrm{Sec}$ & 2,82 & & & & $\mathrm{Sec}$ & 2,43 & & \\
\hline \multirow{2}{*}{$\begin{array}{l}\text { Contestar mal al } \\
\text { docente }\end{array}$} & Pri & 1,50 & \multirow{2}{*}{1,877} & \multirow{2}{*}{, 064} & \multirow{2}{*}{$\begin{array}{l}\text { Realizar acciones } \\
\text { peligrosas }\end{array}$} & Pri & 2,40 & \multirow{2}{*}{, 839} & \multirow{2}{*}{,404 } \\
\hline & $\mathrm{Sec}$ & 1,92 & & & & $\mathrm{Sec}$ & 2,57 & & \\
\hline
\end{tabular}




\begin{tabular}{|c|c|c|c|c|c|c|c|c|c|}
\hline \multirow{2}{*}{$\begin{array}{l}\text { Burlarse de otros } \\
\text { alumnos }\end{array}$} & Pri & 2,80 & \multirow{2}{*}{1,423} & \multirow{2}{*}{, 158} & \multirow{2}{*}{ Interrumpir } & Pri & 1,71 & \multirow{2}{*}{,755 } & \multirow{2}{*}{,452 } \\
\hline & $\mathrm{Sec}$ & 2,51 & & & & $\mathrm{Sec}$ & 1,86 & & \\
\hline \multirow{2}{*}{ Discutir } & Pri & 2,72 & \multirow{2}{*}{, 729} & \multirow{2}{*}{,468 } & \multirow{2}{*}{ Mentir } & Pri & 2,69 & \multirow{2}{*}{2,518} & \multirow{2}{*}{013} \\
\hline & $\mathrm{Sec}$ & 2,57 & & & & $\mathrm{Sec}$ & 2,10 & & \\
\hline \multirow[b]{2}{*}{ Hacer trampas } & Pri & 2,37 & \multirow[b]{2}{*}{,312 } & \multirow[b]{2}{*}{, 755} & \multirow{2}{*}{$\begin{array}{l}\text { Pedir siempre que se } \\
\text { le repitan las } \\
\text { instrucciones }\end{array}$} & Pri & 2,71 & \multirow[b]{2}{*}{2,067} & \multirow[b]{2}{*}{, 041} \\
\hline & Sec & 2,30 & & & & $\mathrm{Sec}$ & 2,26 & & \\
\hline \multirow{2}{*}{$\begin{array}{l}\text { Tener que ser siempre } \\
\text { el primero o el mejor }\end{array}$} & Pri & 3,25 & \multirow{2}{*}{, 290} & \multirow{2}{*}{,772 } & \multirow{2}{*}{ Fumar } & Pri & 1,44 & \multirow{2}{*}{4,161} & \multirow{2}{*}{, 000} \\
\hline & Sec & 3,18 & & & & Sec & 2,42 & & \\
\hline \multirow{2}{*}{$\begin{array}{l}\text { Bullying, maltrato entre } \\
\text { iguales }\end{array}$} & Pri & 2,67 & \multirow{2}{*}{, 824} & \multirow{2}{*}{,412 } & \multirow{2}{*}{ Llevar armas al aula } & Pri & 1,36 & 2077 & 041 \\
\hline & $\mathrm{Sec}$ & 2,86 & & & & $\mathrm{Sec}$ & 1,80 & 2,011 & ,041 \\
\hline Ropa de educación & Pri & 2,86 & 080 & 036 & Exhibir símbolos de & Pri & 1,38 & 1417 & 160 \\
\hline física sucia & $\mathrm{Sec}$ & 2,84 & , 080 & ,930 & bandas o pandillas & $\mathrm{Sec}$ & 1,68 & 1,411 &, 100 \\
\hline Ulerimear & Pri & 2,20 & & & Escribir o pintar en las & Pri & 1,60 & 1450 & \\
\hline Lloriquear & $\mathrm{Sec}$ & 1,68 & 2,540 &, 013 & paredes & $\mathrm{Sec}$ & 1,94 & 1,459 & , 148 \\
\hline Decir continuamente & Pri & 2,49 & 612 & 542 & Robar & Pri & 1,72 & 677 & 500 \\
\hline "no puedo" & $\mathrm{Sec}$ & 2,35 & ,012 &, 542 & & $\mathrm{Sec}$ & 1,86 &, 011 & , 200 \\
\hline Ser nerezoso & Pri & 2,46 & 1250 & 214 & Hahlar & Pri & 2,75 & 297 & 767 \\
\hline ser perezoso & $\mathrm{Sec}$ & 2,73 & 1,250 &, 214 & Hablar & $\mathrm{Sec}$ & 2,82 &, 291 &,$/ 01$ \\
\hline Tener una pobre imagen & Pri & 2,21 & & & & Pri & 2,98 & & \\
\hline de sí mismo & $\mathrm{Sec}$ & 2,26 &, 253 &, 801 & Mostrar risitas tontas & $\mathrm{Sec}$ & 3,05 & ,310 & ,757 \\
\hline Moverse lentamente a & Pri & 2,46 & & & Mercon & Pri & 2,10 & 2526 & \\
\hline propósito & Sec & 2,50 &, 176 &, 861 & Mascar chicles & $\mathrm{Sec}$ & 2,97 & 3,536 & ,001 \\
\hline Olvidar su ropa de & Pri & 2,70 & 697 & 487 & Formar camarillas & Pri & 2,38 & & \\
\hline educación física & $\mathrm{Sec}$ & 2,86 & 691 &, 481 & Formar camarinas & Sec & 2,55 &, 732 & , 466 \\
\hline Ilompr lo opeción & Pri & 3,15 & 1230 & & Faltar a clase o llegar & Pri & 2,16 & 1100 & \\
\hline Llamar la atencion & Sec & 3,41 & 1,239 &, 218 & tarde & $\mathrm{Sec}$ & 2,42 & 1,109 &, $2 / 0$ \\
\hline Mostrarse tímido y & Pri & 2,54 & 546 & 586 & Alterarse cuando & Pri & 2,61 & 180 & 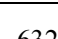 \\
\hline retraído & $\mathrm{Sec}$ & 2,64 &, 540 & ,580 & pierde o se equivoca & $\mathrm{Sec}$ & 2,71 &, 480 & ,032 \\
\hline & Pri & 3,15 & 626 & 533 & & Pri & 2,45 & & \\
\hline Chivarse & Sec & 3,00 &, 026 &, 533 & Pegársele físicamente & $\mathrm{Sec}$ & 1,71 & 3,138 & .002 \\
\hline No participar & Pri & 2,25 & 2,123 & ,036 & al docente & & & 3,150 & \\
\hline & $\mathrm{Sec}$ & 2,69 & & & & & & & \\
\hline
\end{tabular}

* Tipo de Cen: Tipo de Centro

* Pri: Primaria

* Sec: Secundaria

Las conductas encontradas con más frecuencia, según sus valores de media, por los docentes de educación física de los centros de primaria fueron: "Tener que ser siempre el primero o el mejor", "Empujar o pegar a los demás", "Llamar la atención”, "Chivarse”, "Mostrar risitas tontas", "Contestar mal a los alumnos", "Ser provocador", "Ropa de educación física sucia”, "Jugar a lo bruto", "Burlarse de otros alumnos”. Según las respuestas presentadas por los docentes de centros de primaria, los malos comportamientos encontrados con menos frecuencia fueron: "Llevar armas al aula" $(1,36)$, "Exhibir símbolos de bandas o pandillas" (1,38), "Fumar" (1,44), "Contestar mal al docente" $(1,50)$.

Los malos comportamientos de los alumnos encontrados con más frecuencia por los docentes de centros de secundaria fueron: "Llamar la atención", "Tener que ser siempre el primero o el mejor", "Mostrar risitas tontas" y "Chivarse". Según las respuestas dadas por los docentes de centros de secundaria, los malos comportamientos encontrados menos 
frecuentemente fueron: "Lloriquear" $(1,68)$, "Exhibir símbolos de bandas o pandillas" $(1,68)$ y "Pegársele físicamente al docente" $(1,71)$.

También se puede comprobar desde la Tabla 2 que, en la mayoría de los ítems de la escala (en 30 ítems), las puntuaciones medias de los docentes de centros de secundaria son más altas que las de sus compañeros de los centro de primaria. Aunque no se puede decir de forma exacta que hay diferencias significativas entre ellos (primaria / secundaria), se puede llegar a afirmar que según aumenta ls edad del alumno, también aumenta la exhibición de malos comportamientos de los alumnos en el aula. En los 16 ítems restantes, sin embargo, hay más probabilidad que los docentes de centros de primaria se encuentren con estas conductas. Estos ítems se muestran en negrita en la Tabla 2. Los dieciséis ítems en cuestión tienen significados similares y algunos de ellos tienen algún tipo de asociación lo cual posibilita que sea evaluada su relación unos con otros. Al presentar estos ítems uno detrás del otro, nos ayuda a expresar mejor esta realidad:

Empujar o pegar a los demás, Contestar mal a otros alumnos, Gestos obscenos, Burlarse de otros alumnos, Discutir, Ser provocador, Chivarse, Jugar a lo bruto, Hacer trampas, Tener que ser siempre el primero o el mejor, Lloriquear, Decir continuamente "no puedo", Mentir, Pedir siempre que se le repitan las instrucciones, Pegársele físicamente al docente, Ropa de educación física sucia.

Si analizamos los valores medios de las respuestas a los ítems en la Tabla 2, tales como "Ser perezoso", "Tener una pobre imagen de sí mismo", "Mostrarse tímido y retraído", "No participar", "Fingir estar enfermo", “Alterarse cuando pierde o se equivoca", "No seguir las instrucciones", "Mostrar risitas tontas", podemos afirmar que los alumnos de los centros de secundaria son más pasivos, reacios, indiferentes y retraídos que los alumnos de centros de primaria durante las lecciones de educación física.

Lo que interesa de la Tabla 3 es que las puntuaciones medias de las docentes mujeres son más altas que las sus compañeros varones en 29 de los 46 ítems referentes a los malos comportamientos de los alumnos. Se determinó que las docentes se encuentran con los malos comportamientos nombradas en esta escala con mucho más frecuencia que los docentes. De acuerdo con los resultados obtenidos, hubo una diferencia estadísticamente significativa en uno de los 46 ítems. Según el análisis de la prueba t, las docentes mujeres se encontraron con 
la conducta "Contestar mal al docente" con mucho más frecuencia frente a los docentes de educación física varones.

Según las docentes, los malos comportamientos de los alumnos hallados con más frecuencia fueron: "Tener que ser siempre el primero o el mejor" $(3,16)$, "Empujar o pegar a los demás" $(3,15)$, “Contestar mal a los alumnos" $(3,15)$, “Ser provocador" $(3,15)$ y "Llamar la atención". Para los docentes, las conductas encontradas con más frecuencia fueron: "Llamar la atención” $(3,27)$ y “Tener que ser siempre el primero o el mejor" $(3,22)$.

Según las docentes, las conductas que menos se encontraron entre los 46 malos comportamientos identificados fueron: "Llevar armas al aula", "Escribir o pintar en las paredes" y "Exhibir símbolos de bandas o pandillas". Según los docentes la lista de esas conductas es "Exhibir símbolos de bandas y pandillas", "Contestar mal al profesor", y "Llevar armas al aula".

\section{Tabla 3. Evaluación de las puntuaciones medias de los malos comportamientos de los alumnos encontrados por los docentes, según el sexo de éstos}

\begin{tabular}{|c|c|c|c|c|c|c|c|c|c|}
\hline Comportamientos & Sexo & $\begin{array}{c}\text { Med } \\
\text { ia }\end{array}$ & $\mathbf{t}$ & $\mathbf{p}$ & Comportamientos & Sexo & Media & $\mathbf{t}$ & $\mathbf{p}$ \\
\hline \multirow{2}{*}{$\begin{array}{l}\text { Empujar o pegar a los } \\
\text { demás }\end{array}$} & $\mathrm{M}^{*}$ & 3,15 & \multirow[b]{2}{*}{, 521} & \multirow[b]{2}{*}{,603 } & \multirow[b]{2}{*}{ Chulearse } & $\mathrm{M}$ & 2,26 & \multirow[b]{2}{*}{, 779} & \multirow{2}{*}{,438 } \\
\hline & $\mathrm{H}^{*}$ & 3,01 & & & & $\mathrm{H}$ & 2,09 & & \\
\hline \multirow{2}{*}{$\begin{array}{l}\text { Contestar mal a los } \\
\text { alumnos }\end{array}$} & $\mathrm{M}$ & 3,15 & \multirow{2}{*}{1,288} & \multirow{2}{*}{,201 } & \multirow{2}{*}{ Fingir estar enfermo } & $\mathrm{M}$ & 2,46 & \multirow{2}{*}{,345 } & \multirow{2}{*}{, 731} \\
\hline & $\mathrm{H}$ & 2,83 & & & & $\mathrm{H}$ & 2,37 & & \\
\hline \multirow{2}{*}{ Gestos obscenos } & $\mathrm{M}$ & 2,65 & \multirow{2}{*}{1,810} & \multirow{2}{*}{,073 } & \multirow{2}{*}{$\begin{array}{l}\text { No seguir las } \\
\text { instrucciones }\end{array}$} & $\mathrm{M}$ & 2,36 & \multirow{2}{*}{, 675} & \multirow{2}{*}{, 501} \\
\hline & $\mathrm{H}$ & 2,19 & & & & $\mathrm{H}$ & 2,19 & & \\
\hline \multirow{2}{*}{ Jugar a lo bruto } & $\mathrm{M}$ & 2,76 & \multirow{2}{*}{, 105} & \multirow{2}{*}{917} & \multirow{2}{*}{ No cuidar el equipo } & $\mathrm{M}$ & 2,76 & \multirow{2}{*}{, 271} & \multirow{2}{*}{,787 } \\
\hline & $\mathrm{H}$ & 2,79 & & & & $\mathrm{H}$ & 2,83 & & \\
\hline \multirow{2}{*}{ Ser provocador } & $\mathrm{M}$ & 3,15 & \multirow{2}{*}{1,482} & \multirow{2}{*}{,142 } & \multirow{2}{*}{$\begin{array}{l}\text { No ponerse bien en } \\
\text { fila }\end{array}$} & $\mathrm{M}$ & 2,23 & \multirow{2}{*}{,880 } & \\
\hline & $\mathrm{H}$ & 2,78 & & & & $\mathrm{H}$ & 2,45 & & 381 \\
\hline Contestar mal al & $\mathrm{M}$ & 2,12 & & & Realizar acciones & $\mathrm{M}$ & 2,57 & & \\
\hline docente & $\mathrm{H}$ & 1,50 & 2,571 & ,012 & peligrosas & $\mathrm{H}$ & 2,43 & ,591 & ,556 \\
\hline Burlarse de otros & $\mathrm{M}$ & 2,84 & & & Intormumir & $\mathrm{M}$ & 1,96 & 1040 & \\
\hline alumnos & $\mathrm{H}$ & 2,60 & 1,049 &, 297 & Interrumpir & $\mathrm{H}$ & 1,72 & 1,049 & ,297 \\
\hline Diccutir & $\mathrm{M}$ & 2,88 & & & & $\mathrm{M}$ & 2,48 & 122 & 804 \\
\hline Discutir & $\mathrm{H}$ & 2,57 & 1,325 & ,188 & Mentir & $\mathrm{H}$ & 2,44 & ,133 & ,894 \\
\hline & $\mathrm{M}$ & 2,42 & & & Pedir siempre que se & $\mathrm{M}$ & 2,34 & & \\
\hline Hacer trampas & $\mathrm{H}$ & 2,30 &, 526 & ,600 & $\begin{array}{l}\text { le repitan las } \\
\text { instrucciones }\end{array}$ & $\mathrm{H}$ & 2,63 & 1,182 & ,240 \\
\hline Tener que ser siempre el & $\mathrm{M}$ & 3,16 & & & & $\mathrm{M}$ & 2,25 & & \\
\hline primero o el mejor & $\mathrm{H}$ & 3,22 & ,275 &, 784 & Fumar & $\mathrm{H}$ & 1,69 & 1,979 & ,051 \\
\hline Bullying / maltrato entre & $\mathrm{M}$ & 2,70 & 238 & 812 & L lovar armos ol o & $\mathrm{M}$ & 1,66 & 762 & 448 \\
\hline iguales & $\mathrm{H}$ & 2,77 &, 238 &, 813 & Llevar armas al aula & $\mathrm{H}$ & 1,48 &, 762 & 448 \\
\hline Ropa de educación física & $\mathrm{M}$ & 2,69 & 784 & 435 & Exhibir símbolos de & $\mathrm{M}$ & 1,79 & 1640 & 103 \\
\hline sucia & $\mathrm{H}$ & 2,89 & ,784 & ,435 & bandas o pandillas & $\mathrm{H}$ & 1,40 & 1,649 & ,103 \\
\hline & $\mathrm{M}$ & 1,80 & & & Escribir o pintar en las & $\mathrm{M}$ & 1,76 & & \\
\hline Lloriquear & $\mathrm{H}$ & 2,05 & 1,073 & ,286 & paredes & $\mathrm{H}$ & 1,73 & ,105 & 917 \\
\hline Decir continuamente "no & $\mathrm{M}$ & 2,53 & & & Robar & $\mathrm{M}$ & 2,00 & & \\
\hline puedo" & $\mathrm{H}$ & 2,41 &, 534 & ,595 & & $\mathrm{H}$ & 1,69 & 1,301 & 196 \\
\hline & $\mathrm{M}$ & 2,53 & & & & $\mathrm{M}$ & 2,88 & & \\
\hline Ser perezoso & $\mathrm{H}$ & 2,60 &, 267 & ,790 & Hablar & $\mathrm{H}$ & 2,72 & ,592 & ,555 \\
\hline
\end{tabular}




\begin{tabular}{|c|c|c|c|c|c|c|c|c|c|}
\hline \multirow{2}{*}{$\begin{array}{l}\text { Tener una pobre imagen } \\
\text { de sí mismo }\end{array}$} & $\mathrm{M}$ & 2,26 & \multirow{2}{*}{313} & \multirow{2}{*}{, 755} & \multirow{2}{*}{ Mostrar risitas tontas } & $\mathrm{M}$ & 2,92 & \multirow{2}{*}{,429 } & \multirow{2}{*}{,669 } \\
\hline & $\mathrm{H}$ & 2,20 & & & & $\mathrm{H}$ & 3,02 & & \\
\hline \multirow{2}{*}{$\begin{array}{l}\text { Moverse lentamente a } \\
\text { propósito }\end{array}$} & $\mathrm{M}$ & 2,34 & \multirow{2}{*}{, 765} & \multirow{2}{*}{,446 } & \multirow{2}{*}{ Mascar chicles } & $\mathrm{M}$ & 2,64 & \multirow{2}{*}{, 725} & \multirow{2}{*}{,470 } \\
\hline & $\mathrm{H}$ & 2,50 & & & & $\mathrm{H}$ & 2,42 & & \\
\hline \multirow{2}{*}{$\begin{array}{l}\text { Olvidar su ropa de } \\
\text { educación física }\end{array}$} & $\mathrm{M}$ & 2,79 & \multirow{2}{*}{, 252} & \multirow{2}{*}{, 802} & \multirow{2}{*}{ Formar camarillas } & $\mathrm{M}$ & 2,50 & \multirow{2}{*}{,296 } & \multirow{2}{*}{,768 } \\
\hline & $\mathrm{H}$ & 2,72 & & & & $\mathrm{H}$ & 2,42 & & \\
\hline \multirow{2}{*}{ Llamar la atención } & $\mathrm{M}$ & 3,15 & \multirow{2}{*}{,496 } & \multirow{2}{*}{,621 } & \multirow{2}{*}{$\begin{array}{l}\text { Faltar a clase o llegar } \\
\text { tarde }\end{array}$} & $\mathrm{M}$ & 2,38 & \multirow{2}{*}{, 705} & \multirow{2}{*}{,483 } \\
\hline & $\mathrm{H}$ & 3,27 & & & & $\mathrm{H}$ & 2,20 & & \\
\hline \multirow{2}{*}{$\begin{array}{l}\text { Mostrarse tímido y } \\
\text { retraído }\end{array}$} & $\mathrm{M}$ & 2,53 & \multirow{2}{*}{, 253} & \multirow{2}{*}{, 801} & \multirow{2}{*}{$\begin{array}{l}\text { Alterarse cuando } \\
\text { pierde o se equivoca }\end{array}$} & $\mathrm{M}$ & 2,73 & \multirow{2}{*}{, 520} & \multirow{2}{*}{,604 } \\
\hline & $\mathrm{H}$ & 2,58 & & & & $\mathrm{H}$ & 2,60 & & \\
\hline \multirow{2}{*}{ Chivarse } & $\mathrm{M}$ & 2,92 & \multirow{2}{*}{, 740} & \multirow{2}{*}{, 461} & \multirow{4}{*}{$\begin{array}{l}\text { Pegársele físicamente } \\
\text { al docente }\end{array}$} & $\mathrm{M}$ & 2,03 & \multirow{4}{*}{, 557} & \multirow{4}{*}{, 579} \\
\hline & $\mathrm{H}$ & 3,12 & & & & & 2,18 & & \\
\hline \multirow{2}{*}{ No participar } & $\mathrm{M}$ & 2,30 & 584 & 561 & & $\mathrm{H}$ & & & \\
\hline & $\mathrm{H}$ & 2,44 & ,584 & ,561 & & & & & \\
\hline
\end{tabular}

*M: Mujer

*H: Hombre

\section{Discusión}

Como resultado de este estudio podemos argüir que los malos comportamientos de los alumnos encontrados por los docentes de educación se basan en cuatro aspectos concretos. El primero es el aspecto económico representado por no cuidar o usar bien el equipo o la ropa de gimnasia. En el segundo los alumnos muestran mala conducta o se contestan mal unos a otros durante las lecciones. El tercero es que los alumnos insistan en hablar o reírse de manera excesiva. El cuarto son las demandas innecesarias de los alumnos por ganar el favor del docente, e incluye las dos conductas más frecuentes de entre los 42 ítems. Este cuarto aspecto se aproxima al de "Llamar la atención del profesor y de la clase" como el mal comportamiento observado con más frecuencia en el primer curso de educación primaria, mencionado en un estudio de 130 maestros de educación primaria en Izmir (Yıldız y Türnüklü, 2002). Si la tarea o el entorno egocéntrico es organizado por el docente de forma que conduzca el aprendizaje de un mayor número de alumnos, y que los docentes informen de menos problemas, puede que se vean afectadas positivamente también las conductas de los alumnos a la hora de atender a su tarea (Solmon, 1996). También en este estudio, "Tener que ser siempre el primero o el mejor" y "Llamar la atención" fueron definidos como los malos comportamientos de los alumnos encontrados con más frecuencia en un análisis realizado según el tipo de centro para el que trabajaban los docentes y según el sexo de éstos.

Según los datos obtenidos de este estudio, los malos comportamientos de los alumnos menos encontrados por los docentes tienen más que ver con transgresiones disciplinarias que con la estructura de la lección o con el docente. Son situaciones más bien negativas que pueden superarse en cooperación con la gestión del centro. Otro hallazgo positivo es que estas situaciones se encuentran pocas veces o en absoluto. Este hallazgo concuerda con los 
resultados de estudios realizados por Cothran y Kulinna (2007) al igual que Kulinna, Cothran y Regualos (2006) en la región norcentral de EE.UU., con 303 docentes de educación física (173 mujeres, 130 hombres). Según los datos obtenidos del estudio en cuestión, los malos comportamientos de los alumnos encontrados con menos frecuencia, según las puntuaciones medias de las respuestas de los docentes, son: "Pegársele físicamente al docente" $(2,13)$, "Usar el período menstrual como excusa para no participar" (1,96), "Acoso sexual" $(1,90)$, "Escaparse de la clase", "Escribir en las paredes y en las taquillas" $(1,79)$, "Exhibir símbolos de bandas o pandillas" (1,29), "Consumo de drogas" (1,39), "Embarazo" (1,32), "Fumar" $(1,21)$ y "Llevar armas al aula" $(1,21)$.

Otro resultado notable de este estudio realizado en Turquía es que los docentes varones generalmente encuentran malos comportamientos de los alumnos de menos gravedad, frente a lo que encuentran sus compañeras. Kulinna, Cothran, y Regualos (2006) afirman en sus estudios que existen diferencias significativas en las percepciones de los docentes de los malos comportamientos de los alumnos, según su sexo. Mientras las docentes de educación física dicen que a menudo se encuentran con malos comportamientos menos graves, los docentes dicen que ellos a menudo se encuentran con malos comportamientos moderados o graves. Además, los autores subrayan que mediaban tanto el nivel educativo de las clases y el sexo de los docentes. Los profesores tanto varones como mujeres observaban con frecuencia conductas fastidiosas en la educación secundaria. Sin embargo, se informó que las maestras encuentran conductas fastidiosas con más frecuencia que los maestros en el centro de primaria, y que los profesores de educación física se encuentran con más conductas fastidiosas de los alumnos que las profesores en el centro de secundaria. Sin embargo, el resultado de nuestro estudio difiere del estudio llevado a cabo por Y1ldız y Türnüklü (2002), con 130 maestros de primaria en Izmir. En este estudio los investigadores subrayaron que "La frecuencia de encontrarse con malos comportamientos de los alumnos en las aulas no depende del sexo de los docentes, pues tanto hombres como mujeres encuentran los malos comportamientos de los alumnos con igual frecuencia, pero varía el nivel de incomodidad que sienten como resultado de los malos comportamientos de los alumnos, algo que puede explicarse con diferencias particulares del sexo.” (p.162). Puede decirse que este resultado es importante ya que indica que la asignatura de educación física y el ser docente de educación física tienen características distintas. Borg (1998) sugirió que las docentes se preocupan más de las conductas morales que los docentes. Ogden (1998; citado en Stephens, Kyriacou, y Tønnessen, 2005) afirmó que los docentes de mayor edad en los centros educativos de 
Noruega encontraban menor gravedad en los malos comportamientos de sus alumnos que lo que encontraban sus compañeros más jóvenes. Otro hallazgo de este estudio es que los docentes varones encuentran malos comportamientos de mayor gravedad que las docentes. En sus estudios, Stephens, Kyriacou y Tønnessen (2005) notaron una diferencia importante entre los sexos en lo que se refiere a los ítems "Interrumpir otros alumnos" y "Usar el teléfono móvil durante la lección”. Las docentes en prácticas consideraron más inaceptables estos ítems que sus compañeros varones. Las pruebas $t$ sugerían diferencias significativas en tres ítems según la edad de los participantes. Se informó que los ítems "Hablar fuera de turno", "Saltarse las clases o hacer novillos" y "Discutir hostilmente con el docente" eran más inaceptables para menores de 26 años. A la luz de estos hallazgos, se concluyó que "Los docentes de más edad y los docentes varones parecían más tolerantes con los alumnos". La parte de esta interpretación relacionada con el sexo es compatible con los hallazgos de este estudio. Los datos obtenidos en el presente estudio pueden interpretarse como que los docentes varones de educación física en Turquía son más tolerantes con los alumnos que sus compañeras. Infantino y Little (2005) trataron el tema desde la perspectiva de los alumnos y encontraron que las alumnas consideran más fastidiosos los comportamientos mostrados por sus iguales que los alumnos. Las docentes consideran más fastidiosas las conductas "Hablar fuera de turno", "Encontrarse fuera de su sitio" y "Comer", frente a la percepción de los docentes. Estudios de observación directa en educación general (Turnuklu y Galton, 2001) y en educación física (Hardy, Hardy y Thorpe, 1994) respaldaron la teoría de que es más probable que los alumnos varones se vean implicados en incidentes con malos comportamientos. El estudio sobre mala conducta de Hardy, Hardy, y Thorpe (1994) ofreció interesantes hallazgos adicionales, ya que encontraron una relación entre el sexo de los alumnos y el de los docentes. En tres cuartos de los malos comportamientos que implicaron a un solo alumno, el docente era del mismo sexo que el alumno con el mal comportamiento. La investigación sugiere que los docentes varones consideran mayor amenaza a su autoridad el mal comportamiento de un alumno que el mal comportamiento de una alumna. Por otro lado, las docentes pueden preocuparse más por el mal comportamiento de una alumna y pueden centrarse más en ideas tradicionales de lo que debe hacer una "buena alumna".

En cuanto a la diferencia entre malos comportamientos de alumnos que encuentran los docentes de educación física de centros de primaria frente a los de secundaria, se observa una mayor presencia de conductas consideradas dentro del ámbito de acciones disciplinarias en centros de secundaria que en los centros de primaria. Es un hecho conocido que a los 
adolescentes de educación secundaria les gusta ser el centro de atención y que otros se fijen en ellos. Sin embargo, es preocupante que ellos no traten de satisfacer este deseo a través del logro en la asignatura. Según las respuestas de los docentes de educación física a los ítems "Ser perezoso", "Tener una pobre imagen de sí mismo", "Mostrarse tímido y retraído", "No participar", "Fingir estar enfermo", "Alterarse cuando pierde o se equivoca", "No seguir las instrucciones" y "Mostrar risitas tontas", podemos concluir que los alumnos de centros secundarios son más pasivos, reacios, indiferentes y retraídos que los alumnos de centros de primaria. Según un hallazgo de Gibbs y Gardiner (2008), en su estudio sobre malos comportamientos de los alumnos con docentes de primaria y secundaria británicos e irlandeses, existían diferencias estructurales considerables entre las opiniones de los docentes de primaria y los de secundaria. Según los docentes de primaria, los malos comportamientos son determinados por factores del hogar y de familia al menos al mismo nivel que por los docentes y otros adultos.

Otro hallazgo que puede concluirse de este estudio es que con mayor edad de los alumnos, hay un aumento y a una diversidad en las malas conductas que muestran. Sin embargo, esta afirmación varía según los tipos de malos comportamientos. Turnuklu y Galton (2001) sugieren que la incidencia difiere en dos malos comportamientos: "movimiento inapropiado" y "hablar ruidosamente o cuando no se permite". Según el estudio llevado a cabo por Turnuklu y Galton (2001), el "movimiento inapropiado" en el aula es más frecuente entre los alumnos más jóvenes que entre los mayores. Por otro lado, el "hablar ruidosamente o cuando no se permite" es una mala conducta más frecuente entre los alumnos mayores que entre los alumnos más jóvenes. Little (2005), en uno de sus estudios donde trata de determinar las percepciones de los docentes de secundaria sobre las malas conductas de los alumnos, sostiene que en Australia se observa que los alumnos mayores de edad presentan unos malos comportamientos bastante distintos a los malos comportamientos de los más pequeños. En cuanto a las malas conductas "Bullying / maltrato entre iguales", "Conducta no relacionada con la tarea", "Oposición al docente”, Bru, Stephens, y Torsheim (2002) afirman que existe diferencias según el nivel del curso y añaden que estos tres tipos de malas conductas se observan más frecuentemente entre alumnos del último ciclo de secundaria que entre los alumnos del último ciclo de primaria. Según Little (2005), esta distinción entre los aprendices más jóvenes y los de mayor edad se debe a las demandas académicas y a una mayor atención de los docentes a las conductas de los alumnos. Little (2005) enfatiza que, según se hacen mayores los aprendices, mayores son las demandas académicas y mayores son las exigencias 
de los docentes de secundaria en cuanto a la atención y a las conductas relacionadas con las tareas, frente a las malas conductas dentro del aula. Otra explicación por la cual los alumnos de 14 a 18 años presentan más malos comportamientos que los alumnos más pequeños de primaria y de secundaria es que están viviendo una etapa de estrés en sus vidas ya que experimentan más demandas académicas, sociales y de su entorno (Miller, Ferguson, y Byrne, 2000). Pierangelo y Giuliani (2000) sugieren que todas estas demandas académicas, sociales y del entorno producen estrés en la vida de los alumnos, y éstos tienen grandes dificultades a la hora de afrontar este estrés y de expresar sus sentimientos. Esta situación psicológica provoca que los alumnos de 14 a 18 años se comporten de forma disruptiva dentro de las aulas. Esto lo respaldan los hallazgos de Houghton, Wheldall, y Merrett (1988): cambios en los malos comportamientos de los alumnos según éstos se hacen mayores pueden deberse al desarrollo evolutivo del alumno. Todos los resultados de estos estudios comentados arriba pueden reflejarse en los hallazgos del estudio presente sobre las clases de educación física en Turquía. Es necesario investigar más sobre este tema en Turquía.

Según los resultados de la prueba t entre grupos independientes, realizada con datos referentes a los malos comportamientos de los alumnos encontrados por los docentes de educación física y en base al tipo de centro, hubo diferencias estadísticamente significativas en 11 de los 43 ítems. Según los resultados del análisis de la prueba t, los ítems "Mascar chicles", "Chulearse", "Fingir estar enfermo", "No participar", "Fumar", y "Llevar armas al aula" fueron las conductas más encontradas con diferencia $(p<.05)$ por los docentes de secundaria, mientras que los ítems "Empujar o pegar a los demás", "Lloriquear", "Mentir", "Pedir siempre que se le repitan las instrucciones" y "Pegársele físicamente al docente" fueron más encontradas con más frecuencia por los docentes de primaria. Esta situación que encuentran los docentes de primaria puede verse como natural al considerar las edades de los niños de primaria. Empujar o pegar a los demás, hacerles daño presentando conductas (obscenas) hacia ellos sin pensar en su significado moral, y jugar a lo bruto, son situaciones reconocidas especialmente por los docentes de primaria. Turnuklu y Galton (2001) concluyeron que ciertos malos comportamientos que se encuentran con frecuencia en los alumnos varían según la edad de los alumnos, y que se debería al desarrollo cognitivo de éstos. Los autores afirmaron que con el desarrollo de los alumnos, sus malos comportamientos cambian de los no verbales a los verbales. Esto se atribuyó a la edad de los alumnos y se ilustró con el contraste evidente que existe entre el ruido y el hablar fuerte, y el movimiento inapropiado. Otro hallazgo interesante fue que la iluminación del aula afecta el 
aprendizaje de los alumnos durante diferentes periodos del día. Sus conductas de atención a la tarea aumentaban y se fortalecían por la tarde más que por la mañana. Los docentes de ambos países afirmaron que predominaba las mismas cuestiones de malos comportamientos en los alumnos. Las asignaturas "Música", "Educación Física" y "Plástica" se consideraban provocadoras de los malos comportamientos. Estas asignaturas comienzan generalmente después de lecciones más formales como "Ciencias Naturales", "Matemáticas", "Lengua Turca”, "Inglés” y "Ciencias Sociales”. Es posible que después de recibir estas lecciones más formales, los alumnos se sientan con más libertad y relajados. Además, los docentes de estas tres asignaturas muestran más la tolerancia los otros docentes. Puede que esta actitud también facilite la aparición de los malos comportamientos. Ding et al. (2008) afirmaron que los docentes de centros de primaria y secundaria consideran más fastidiosas y frecuentes las conductas de "Soñar despierto, no estar atento, quedarse sentado sin contestar a ninguna pregunta". En este estudio, los docentes de los primeros cursos de primaria indicaron como la segunda conducta más frecuente y fastidiosa el "Hablar fuera de turno". Aunque el hablar fuera de turno fue la segunda mala conducta encontrada con más frecuencia por los docentes de los últimos cursos de primaria y de secundaria, no fue aceptada como la segunda conducta más fastidiosa. Por ejemplo, los docentes de los últimos cursos de primaria consideraron el "Quejarse de los deberes" como la segunda conducta más fastidiosa, los docentes de centros de secundaria concluyeron que "Jugar con objetos personales" y "Ser lento" eran tan fastidiosas como "Hablar fuera de turno". "Hablar fuera de turno" de ninguna manera es reconocido como factor significativo por los docentes de secundaria. Según éstos, los comportamientos "Soñar despierto", "Hablar o bromear", "Dormir o mirar por la ventana" y "Jugar con objetos personales" son más fastidiosos que "Hablar fuera de turno". Parece ser que la frecuencia de la conducta "Hablar fuera de turno" disminuye con mayor nivel educativo. Ho y Leung (2002) examinaron la percepción de docentes de secundaria en Hong Kong utilizando el mismo instrumento que había usado en su estudio con docentes de primaria (Leung y Ho, 2001). Los resultados mostraron que los docentes de secundaria ocupaban menos tiempo en la gestión del aula que los docentes de primaria. En cuanto a los malos comportamientos más problemáticos y frecuentes, los hallazgos de este estudio concuerdan con el estudio anterior con docentes de primaria (Leung y Ho, 2001): los dos comportamientos más elegidos fueron todavía el hablar fuera de turno (más disruptiva: 29,8\%; más frecuente: 38,5\%) y falta de atención (más disruptiva: 19,3\%; más frecuente: $19 \%)$. 
En el estudio de Little (2005), ella informó que los docentes creen que las conductas más fastidiosas dependen de la edad de los alumnos. Según los docentes, "hablar fuera de turno" fue la conducta más fastidiosa entre alumnos de 7-8 años. Después siguen "Estorbar a otros" y "Desobedecer". Entre los alumnos de 9-10 años, "Hablar fuera de turno" vuelve a encabezar la lista mientras que "Ser holgazán" resultó ser el segundo y "Estorbar a otros" el tercero. La conducta más fastidiosa entre los alumnos de 11-12 años fue "Ser holgazán". A ésta le siguen "Hablar fuera de turno" y "Llegar tarde".

Como conclusión, este estudio subraya que los malos comportamientos de los alumnos menos se encontraban en las aulas pueden eliminarse con la cooperación de la gestión del centro en lugar de tratarlos dentro de la estructura de la lección o por el docente. Al mismo tiempo, las docentes en general se encontraron con más malas conductas de alumnos de mayor gravedad que sus compañeros varones. Los docentes de educación física participantes en esta investigación afirman que los alumnos de centros de secundaria son más pasivos, reacios, indiferentes y retraídos durante las lecciones de educación física que los alumnos de centros de primaria. En general, según aumenta la edad de los alumnos, también disminuyen los malos comportamientos de los alumnos. Los malos comportamientos varían según el curso escolar.

Finalmente, los malos comportamientos de los alumnos incluidos en la escala recibieron valores similares y no se encontraban comportamientos ni muy por abajo ni muy por encima de la media. Las siguientes son sugerencias para futuras investigaciones en este tema:

Se podría realizar un estudio exhaustivo para determinar cuál de los sexos muestra estos malos comportamientos con mayor frecuencia, o con qué frecuencia los muestra. Una comparación de estudios que abarcan una geografía más amplia y un mayor número de sujetos con los resultados de este estudio podría aportar conclusiones más fiables y así podríamos tener una idea sobre las diferencias y similitudes entre regiones. Podría llevarse a cabo investigación vivencial y cualitativa para poder proponer sugerencias para reducir o prevenir los malos comportamientos de los alumnos en lecciones de educación física.

Por último, las siguientes sugerencias pueden ser de beneficio para los docentes de educación física para minimizar los malos comportamientos de los alumnos en sus clases. En 
cuanto a las clases en sí, la gestión del grupo clase incluye las fases de reunirse en el gimnasio, el patio del centro o el aula donde se dará la clase; actividades menores de calentamiento o transición durante la lección; traslado de equipos; y el cierre de la lección. Generalmente, durante el cierre (finalización) de la clase, se ofrece evaluación o consejos a los alumnos y se les permite prepararse para su siguiente asignatura. Al principio del curso se le debe enseñar a los alumnos cómo recoger el gimnasio y poner en orden todo el equipo en la última fase de la clase, para que los alumnos sepan qué es lo que deben hacer y se acostumbren a realizar estas actividades al final de cada lección. Este orden hará que tanto los docentes como los alumnos se sientan cómodos a lo largo del curso. El derecho a retirarse de las actividades de educación física debe darse únicamente a alumnos que sufran de algún problema de salud en esos momentos.

Algunos alumnos no quieren traer o cargar con su ropa de gimnasia, zapatos y otro equipamiento para las clases de educación física. Además, aún cuando traigan toda la ropa necesaria, zapatos y equipo, algunos alumnos pueden sentirse tímidos al quitarse el uniforme escolar y ponerse la ropa de deporte cerca de otros alumnos. Se sienten incómodos y esta situación puede afectarles de forma negativa. Los alumnos en esta situación visten su ropa de gimnasia encima de su uniforme escolar y así asisten a las clases de educación física, lo que puede causar problemas de salud no deseados como sudoración excesiva, pronto agotamiento y limitaciones de movimiento. Todo esto puede causar que los alumnos tengan dificultades a la hora de participar en las actividades y puede llevar a que los alumnos actúen de forma no deseada. Por lo tanto, los docentes de educación física deben tener cuidado con tales temas.

Para gestionar toda la clase de forma efectiva, los docentes de educación física deben tener las competencias suficientes en su campo, la creatividad y capacidad suficientes para aplicar las actividades de enseñanza y aprendizaje de manera correcta y compatible con el nivel de los alumnos, y tomar de antemano todas las precauciones necesarias para la seguridad de los alumnos. La planificación exhaustiva de cada sesión es importante para la gestión del aula.

Entre los alumnos, hay los que prefieren un docente servicial que no espera demasiado de ellos. Los docentes de educación física deben tener en mente esta realidad. Los docentes de educación física deben llamar a los alumnos por su nombre si desean transmitir una imagen de docente cariñoso, sincero y servicial para con sus alumnos. Sin embargo, abrazar o tocar a 
los alumnos pueden causar malentendidos. Por lo tanto, los docentes no deben excederse en este tipo de conductas sinceras.

Antes de nada, los docentes de educación física deben hacer que los alumnos les respeten. Sólo después se puede ofrecer a los alumnos un entorno en el cual existe amor hacia el docente, la lección y los alumnos. Este entorno de respeto y amor debe ayudar a los docentes a afrontar los malos comportamientos de los alumnos y a gestionar la clase eficazmente a lo largo del curso. La mejor forma para crear tal entorno de enseñanzaaprendizaje en las clases de educación física es al establecer las reglas, responsabilidades, obligaciones y limitaciones, y fijar los objetivos y normas del aula en la primera lección al empezar el curso. Estas son normas de "protección y prevención”, restringiendo las conductas de los alumnos durante las sesiones, y normas de respeto, al obedecer las instrucciones como ¡Para!, ¡Mira!, ¡Escucha!, respectivamente. Estas normas, modelos de conducta e instrucciones ayudan al uso eficaz del tiempo de la clase.

Durante las sesiones, los docentes de educación física a veces necesitan interrumpir la actividad y captar de nuevo la atención de los alumnos por medio de un aviso. Para lograr esto, debe enseñársele a los alumnos algunas instrucciones específicas, para que cada vez que ellos escuchen estas instrucciones, actúen de la manera que se espera de forma automática. Algunas de estas instrucciones son las de Atención/Silencio, Juntaos, y Vuelve a tu Sitio. Especialmente para los grupos de alumnos más jóvenes se debe identificar la instrucción de Atención/Silencio y enseñarla a los alumnos. Estas instrucciones específicas deben enseñarse a los alumnos en la primera clase del curso, y los docentes de educación física deben ser consecuentes y estrictos al aplicar estas instrucciones en las aulas. De este modo, los docentes pueden volver a captar la atención de los alumnos cuando éstos comienzan a perder su motivación.

Roles como el de líder, capitán, jugador del equipo, y juez pueden distribuirse entre los alumnos, haciéndoles participar en todas las actividades de forma activa. Sobre todo los alumnos con menor capacidad o que sufren de obesidad pueden desempeñar los papeles de juez, árbitro o asesor, integrándoles así en las actividades de forma social y cognitiva.

En la aplicación de todas estas sugerencias sobre la eficaz gestión del aula, es muy importante la buena comunicación entre los docentes y los alumnos. Si los docentes tienen 
una capacidad de escuchar bien desarrollada, podrán comunicarse fácilmente y establecer lazos de empatía con sus alumnos. Una buena comprensión de los alumnos se facilita practicando la escucha efectiva, donde el docente de educación física repite en sus propias palabras los mensajes verbales y no verbales de sus alumnos.

Puede ser de beneficio para los docentes de educación física asistir a programas de formación continua que traten sobre los comportamientos de los alumnos, la psicología del alumno, la gestión del aula y la comunicación eficaz.

\section{Referencias}

Atıc1, M. (2007). A small-scale study on student teachers' perceptions of classroom management and methods for dealing with misbehaviour. Emotional and Behavioural Difficulties, 12(1), 15-27.

Borg, MG (1998). Secondary school teachers' perception of pupils' undesirable behaviors. British Journal of Educational Psychology, 68(1), 67-79.

Bru, E., Murberg, TA, y Stephens, P. (2001). Social support, negative life events and pupil misbehaviour among young Norwegian adolescents. Journal of Adolescence, 24, 715727.

Bru E., Stephens, P., y Torsheim, T. (2002). Students' perceptions of class management and reports of their own misbehavior. Journal of School Psychology, 40(4), 287-307.

Charles, CM (1992). Building classroom discipline: from models to practice. (4. ed.) Londres: Longman.

Cothran, D.J. y Kulinna, PH (2007). Students' reports of misbehavior in physical education. Research Quarterly for Exercise and Sport, 78(3), 216-224.

Ding M., Li Y., Li X., y Kulm G. (2008). Chinese teachers' perceptions of students' classroom misbehaviour. Educational Psychology, 28(3), 305-324.

Gibbs, S., y Gardiner, M. (2008). The structure of primary and secondary teachers' attributions for pupils' misbehaviour: a preliminary cross-phase and cross-cultural investigation. Journal of Research in Special Educational Needs, 8(2), 68-77.

Goyette, R., Dore, R., y Dion, E. (2000). Pupils' misbehaviors and the reactions and causal attributions of physical education student teachers: a sequential analysis. Jounal of Teaching in Physical Education, 20, 3-14. 
Hardy, C. A., Hardy, C. E., y Thorpe, R. D. (1994). Pupil misbehavior in secondary school mixed-sex physical education lessons. British Journal of Physical Education Research Supplement, 15, 7-11.

Ho, C., y Leung, J. (2002). Disruptive classroom behaviors of secondary and primary school students. Educational Research Journal, 17, 219-233.

Ho, IT (2004). A comparison of Australian and Chinese teachers' attributions for student problem behaviors. Educational Psychology, 24, 375-391.

Houghton, S., Merrett, F., y Wheldall, K. (1988). The attitudes of British secondary school pupils to praise, rewards, punishments and reprimands: A further study. New Zealand Journal of Educational Studies, 23, 203-215.

Infantino, J., y Little, E. (2005). Students' perceptions of classroom behavior problems and the effectiveness of different disciplinary methods. Educational Psychology, 25, 491508.

Kulinna, P. H., Cothran, D., y Regualos R. (2003). Development of an Instrument to Measure Student Disruptive Behavior. Measurement in Phystcal Education and Exercise Sclence, 7(1), 25-41.

Kulinna, P. H., Cothran, D., y Regulalos, R. (2006). Teachers' reports of students misbehavior in physical education. Research Quarterly for Exercise and Sport, 77(1), $32-40$.

Kyriacou, C., Avramidis, E., Høie, H., Stephens P., y Hultgren, A. (2007). The development of student teachers' views on pupil misbehaviour during an initial teacher training programme in England and Norway. Journal of Education for Teaching, 33(3), 293307.

Leung, J., y Ho, C. (2001). Disruptive behavior perceived by Hong Kong primary school teachers. Educational Research Journal, 16, 223-237.

Lewis, R., Romi, S., Qui, X., y Katz, Y. (2005). Teachers' classroom discipline and student misbehavior in Australia, China and Israel. Teaching and Teacher Education, 21, 729-741.

Liljequist L., y Renk K. (2007). The relationships among teachers' perceptions of student behaviour, teachers' characteristics, and ratings of students' emotional and behavioural problems. Educational Psychology, 27(4), 557-571.

Little, E. (2005). Secondary school teachers' perceptions of students' problem behaviours. Educational Psychology, 25, 369-377. 
Miller, A., Ferguson, E., y Byrne, I. (2000). Pupils' causal attributions for difficult classroom behaviour. British Journal of Educational Psychology, 70, 85-96.

Pierangelo, R., y Giuliani, G. A. (2000). Why your students do what they do and what to do when they do it: A practical guide for understanding classroom behaviour. Champaign Illinois: Research Press.

Solmon, M.A. (1996). Impact of motivational climate on students' behaviors and perceptions of a physical education setting. Journal of Educational Psychology, 88(4), 731-738.

Supaporn, S., Dodds, P., y Griffin, L. L. (2003). An ecological analysis of middle school misbehavior through student and teacher perspectives. Journal of Teaching in Physical Education, 22(3), 328-349.

Supaporn, S. (2000). High school students' perspectives about misbehavior. Physical Educator, 57, 124-135.

Stephens, P., Kyriacou, C. y Tønnessen, F. E. (2005). Student teachers' views of pupil misbehaviour in classrooms: a Norwegian and an English setting compared. Scandinavian Journal of Educational Research, 49(2), 203-216.

Turnuklu, A., y Galton, M. (2001). Students' misbehaviors in Turkish and English primary classrooms. Educational Studies, 27, 291-305.

Yıldız, V., y Türnüklü, A. (2002). İlköğretim okullarında öğretmenlerin sınıflarında karşılaştıkları öğrencilerin istenmeyen davranışları ve bu davranışların öğretmenleri rahatsız etme düzeyi. Eğitim Araştırmalart-Eurasian Journal of Educational Research, 3(9), 156-163. 
[Página en blanco por razones de paginación] 